\title{
Seven policy directions that support forest ecosystem research
}

\author{
by Ole Hendrickson ${ }^{1}$
}

\section{Introduction}

The phrase "forest ecosystem" is often used, but it is not necessarily well understood or supported by enabling policies. There is a danger that if "forest ecosystem" is used synonymously with "forest," key underlying issues and concepts will be lost. Forest ecosystem research is laden with policy implications. Ecosystem concepts such as emergent properties and adaptation to changing environments are central themes in modern society. They could be powerful forces to unite forest policy and science. A more thorough understanding of these concepts and appropriate supporting policies are needed to meet the challenge of sustainable forest management.

I will examine seven aspects of the relationship between forest ecosystem concepts and forest policy:

1. A forest ecosystem integrates a wide range of values.

2. The paradigm of continuous change forces us to rethink management strategies.

3. Adaptive management treats ecosystems as experiments. 4. Moving from local to global scales reveals emergent properties.

5. Managing information is the key to managing landscapes. 6. Nature provides valuable regenerative and absorptive services.

7. Socioeconomic units are ecosystems and vice versa.

\section{A Forest Ecosystem Integrates a Wide Range of Values}

The ecosystem is a powerful integrating concept capable of promoting rapid scientific advances if research is properly understood and supported:

Explosive growth in knowledge and understanding can occur when conceptual links are made across disciplines, and across different levels of biological organization. Developments are needed that will allow the integration of taxonomic and ecological data about organisms with geographic, meteorological, and other datasets. (OECD Megascience Forum 1998)

Eugene Odum, a founder of modern ecology, maintains that scientific advances occur largely at interfaces between disciplines. He was an early champion of linking ecology and economics. Ecological economics is now a dynamic and exciting area (see "Socioeconomic units are ecosystems — and vice versa," below).

Forestry was interdisciplinary before this became fashionable. Fish and wildlife management, hydrology, meteorology, and soil science were once considered core subjects for forestry. Today, they are more relevant than ever to sustainable forest management. Diversity is integral to the forestry curriculum.

\footnotetext{
${ }^{1}$ Natural Resources Canada, Canadian Forest Service, Science Branch, 580 Booth Street, Ottawa, Ontario K1A 0E4. E-mail: ohendric@nrcan.gc.ca
}

Unfortunately, this breadth of expertise has been greatly eroded in university forestry programs and government forest research organizations.

The public values forests because they are tangible, beautiful, complex, diverse, and mysterious. Forestry is struggling to maintain its identity and visibility as a discipline. If forest research organizations retreat to do "what we

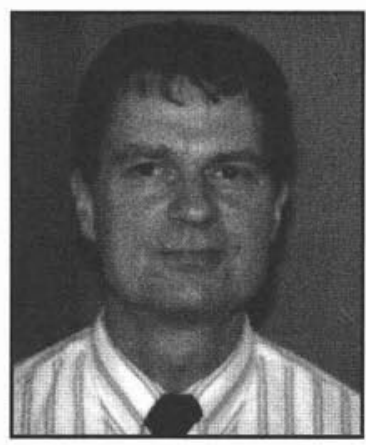
know best - grow trees," there will only be further losses in status. Ecosystem science embraces complexity and diversity. Forestry must do so as well. This will require reviewing research priorities and filling gaps.

\section{The Paradigm of Continuous change Forces us to Rethink Management Strategies}

One of the underlying paradigms of ecology has shifted that of the "balance of nature." Ecologists once believed that ecosystems developed in predictable fashion towards stable climaxes as the normal state of nature. But modern ecology emphasizes the change is the only constant. We cannot eliminate natural disturbances, so we must incorporate them in our management planning.

Botkin (1997) criticizes forestry and fishery agencies for making simple assumptions regarding sustained yield management. If nature is highly stable and predictable, harvest levels can be set by estimating the carrying capacity of a particular area, using height over age curves or similar means. Cut down the forest, and a similar one will grow at a similar rate. Long-term monitoring and research would be largely superfluous in a hypothetical unchanging world. But this view is false:

Nature is characterized by change, not constancy...If we are to conserve and manage our living resources, then we must understand the naturalness of change, and this requires that we move away from the ancient and pervading myth of the balance of nature. (Botkin 1997)

Canadian ecologists have been in the forefront of those who have challenged the myth of the balance of nature. The view that there is an innate biological tendency to achieve stable, climax systems is hard to maintain when one considers the boreal forest, with its periodic fires and spruce budworm outbreaks. C.S. Holling (1992) has been one of the foremost champions of the paradigm that ecosystems undergo natural cycles of destruction, reorganization, and growth.

Awareness is also growing that human beings are increasing the instability of ecosystems. It becomes increasingly urgent to determine whether changes are exceeding the natural limits of variation; and, if so, what we should do about it:

Increased societal and scientific interest in issues such as global change, biodiversity, and sustainability are causing 
ecologists to question how ecological patterns and processes vary in time and space, and to understand the causes and consequences of this variability. (Michener et al. 1997)

By abandoning the balance of nature paradigm,

...we are not helpless to make forecasts and set policies for a dynamic ecosystem; just the opposite. By learning to understand the dynamic of these systems, we can make better forecasts and make better laws and policies than we ever could before. (Botkin 1997)

Policy makers have picked up on the theme that change is inevitable and natural. Government tells industry that to be competitive it must monitor trends, build flexible production systems, hire and train employees with a greater breadth of knowledge who can adapt to change. Vast sums of public money are invested in tracking the ups and downs of the business world.

Everyone agrees that it is essential for governments to maintain our systems of economic indicators. There must be an equal commitment to maintain indicators of the state of forests and other ecosystems - they are essential for our survival.

\section{Adaptive Management Treats Ecosystems as Experiments}

Policy makers are aggressively promoting "adaptive management" (or the similar term, "ecosystem management") as the newest concept in forestry:

Sustainable forest management requires an adaptive management approach, following exemplary forest practice that is grounded on the best available scientific knowledge. (CCFM 1998)

Adaptive management is consistent with the current trend to decentralize decision-making authority. It is a reaction against top-down, bureaucratic attempts to impose general forestry prescriptions without taking account of the diversity of local forest conditions.

Most foresters welcome increased local responsibility and flexibility. But adaptive management also implies local accountability, and a commitment to documenting performance:

Learning from an adaptive approach requires keeping track of what works and what does not work...adaptive ecosystem management combines familiar experimental approaches to forest management with new scientific concepts and information technologies. (Hendrickson 1995)

Local decision-makers need help in using information technologies to record management activities as they are implemented on the ground. They also need access to new scientific concepts. To remain relevant in the age of adaptive management, forestry agencies must strengthen their commitment to managing scientific information:

"adaptive management"....means that one learns as one goes along and modifies policies on the basis of new information.

Scientific research becomes an integral part of conservation and management. (Botkin 1997)

Scientific research organizations do not always practice exemplary information management. Data files may be discarded after a journal article is published, even though they are the basis for future learning activities. For research to become an inte- gral part of forestry, forest researchers must set and follow the highest possible information management standards.

\section{Moving from Local to Global Scales Reveals Emergent Properties}

There is a risk that adaptive management will be promoted by policy makers as a way to divest government responsibility for forestry. If management practices are best formulated at the local level, with the participation of local communities, what is there for a central government (or research organization) to do?

The answer is that forest ecosystems must be examined at a variety of scales, from local to global. Efforts to increase local decision making authority are happening at the same time as efforts to develop international certification standards, to rally support for an international forest convention, and to develop criteria and indicators of sustainable forest management.

Ecosystems are more than the sum of their parts. The ability of forests to modify temperature, hydrologic cycles, and the composition of the atmosphere is not revealed by studying individual forest stands. Without information from other regions, a forester has no way of knowing whether a local vegetation type is globally abundant or critically endangered. Data from earth observation satellites, combined with increasing computer data processing power and geographic information systems, now make it possible for global ecosystem science to provide a level of detail relevant for forest planning at a landscape level:

As ecology comes of age and embraces global remote sensing technologies, it will be clearer what we need to do and clearer that we need to act. (May 1998)

Forest research organizations must promote the integration of top-down technologies and on-the-ground approaches at a variety of scales. The concept of "metadata" - data about data - is central to making this happen:

Metadata provide the information that is critical for expanding the scales at which ecologists work. Temporal comparisons among sites, statistical replication, and comparisons within and among sites all depend upon the availability of sufficient metadata...Similarly, ground-based reference data from multiple sites are frequently used to calibrate or support analyses of remotely sensed data, thereby expanding the spatial domain from the site to the landscape, region or globe. (Michener et al. 1997)

\section{Managing Information is the Key to Managing Landscapes}

With people casually tossing around phrases such as "knowledge-based economy" and "global information society," it can be easy to forget the growing environmental challenges facing our planet. Ecosystem scientists suggest that

Future investments by the government's computing, information, and communications program... should be concentrated in the area of biodiversity and ecosystems information. This Federal investment will enable agencies to manage the biological environment in better ways, and will very likely spin off new technologies that can be exploited by the private sector to benefit the US economy. (President's Council of Advisors on Science and Technology 1998) 
Results of ecosystem research and monitoring do not rapidly go out of date, unlike advances in other areas such as medical research. And these results are irreplaceable, because the habitats where studies were conducted will have changed naturally or by human activities - since the research was done. Botkin (1997) goes further, arguing that the paradigm of continually changing ecosystems will force us to rethink our scientific methods:

The new approach to conservation and management of natural resources is to search for available data, to analyze those data, and to let generalizations emerge from the data analysis. In a way, this is a reversal of the storybook scientific method, in which a scientist poses a hypothesis and then goes out to test it. (Botkin 1997)

If scientists truly believe in the importance of basic research and monitoring, and the serendipitous advances that may come from them, why do they fail to place sufficient emphasis on documenting and preserving their findings? There are three basic explanations for this failing:

Holders of biological data must make those data available. Although the basic principles of science encourage them to do so, barriers exist in the form of 1) the costs of entering data, 2) ignorance of proper mechanisms for making data available, and 3) fear that data will be improperly used. (OECD Megascience Forum 1998)

Every forest research manager must address these issues. Ecosystem information can not be effectively stored in a far-off warehouse - each individual establishment must do its part, while accepting the need for standardization. Appropriate information management strategies for forestry are different from those for domains such as high-energy physics:

Biological informatics differs from other large-scale scientific efforts, because developments will be distributed rather than sited at a single location. Funding structures should be intermediate between a fully centralised model, in which a single structure receives and manages all resources, and a completely loose scheme in which the lack of coordination provides only a perception of global objectives but not the concerted action to achieve them. (OECD Megascience Forum 1998)

\section{Nature Provides Valuable Regenerative and Absorptive Services}

Canada's National Forest Strategy calls for broadening of the scope of inventories and information on the so-called "non-timber features" of forests. It acknowledges that

...forests provide a number of functions essential to life on this planet. For example, they maintain the chemical balance of soil, air and water, stabilize the climate, recycle nutrients, break down pollutants, clean the air and water, and are vital to watershed protection, soil formation, carbon storage and the habitat for wildlife. (Canadian Council of forest Ministers 1998)

Recognition of the importance of these "free" life support services is growing (e.g., Myers 1997). A recent effort to assign dollar values to them (Constanza et al. 1997) can be criticized on both economic and philosophical grounds, but it sug- gests that the value of ecosystem services surpasses the total value of all measured global economic activity. This message is beginning to make its way into the top levels of government:

...natural capital has been shown to be the source of a very large percentage of human economic wealth. (President's Council of Advisors on Science and Technology 1998)

Most people probably think this is just common sense. Without healthy, functioning ecosystems, life on earth would cease to exist. But increased attention to life support services provided by forests is coming as well from specific concerns, such as climate change:

More than half of the carbon dioxide produced by the combustion of fossil fuel does not accumulate in the atmosphere, but is removed and returned to nature. Proper management of forests... can significantly increase this carbon dioxide removal and storage service. Research suggests that this service is provided best by ecosystems with high biodiversity. (President's Council of Advisors on Science and Technology 1998)

Another major issue is the role of forest ecosystems in moderating flood events:

Living vegetation, with its deep roots and above-ground evaporating surface, serves as a giant pump, returning water from the ground to the atmosphere. If this pump is missing or lowered in volume, stream flow increases, sometimes to disastrous levels. A study conducted by the non-governmental organization American Forests... found that a 20\% loss of trees and other vegetation in the Atlanta metropolitan region produced an increase in stormwater runoff of 4.4 billion cubic feet. At $\$ 0.50$ per square foot, it would cost at least $\$ 2$ billion to build containment facilities capable of controlling this water. (President's Council of Advisors on Science and Technology 1998)

Table 1 distinguishes between absorptive services and regenerative services of ecosystems. Absorption of rain, wind, carbon, pollutants, etc. can be viewed as system-level phenomena. Forest research organizations tend to be weak in these areas. In contrast, regenerative services are best studied at the organism level, where forest research organizations are traditionally strong.

\section{Socioeconomic Units Are Ecosystems — and Vice Versa}

Given that ecosystem concepts are laden with policy implications, it is not surprising that a new discipline has emerged that views socioeconomic units as ecosystems. Herman Daly is one of the founders of this discipline, known as ecological economics. He warns that current economic policies will soon collide head-on with a decreasing capacity of ecosystems to supply life-support services:

As the economy expands physically, it assimilates into itself an ever greater proportion of the total life space and the total matter/energy of the ecosystem. Less is therefore available to all other species to provide the services we depend upon, such as photosynthesis, to mention only the most important. At some point well before the boundaries of the growing subsystem coincide with the total system, we will have 
Table 1. Some of nature's services provided by forest ecosystems

\begin{tabular}{ll}
\hline Absorptive services & Regenerative services \\
\hline Flood control (water) & Transpiration (water) \\
Carbon sinks (carbon dioxide) & Photosynthesis (plant cells, oxygen) \\
Assimilation of pollutants & Pollination (organisms) \\
$\quad$ (heavy metals, acid rain, etc.) & Seed dispersal (organisms) \\
Climate moderation & Biocontrol (populations) \\
$\quad$ (wind, solar energy, etc.) & Decomposition/nutrient cycling \\
& (soil formation) \\
\hline
\end{tabular}

sacrificed life-support services that are far more valuable than the extra commodity services that we got in return. (Daly 1996)

Daly is not optimistic about the prospects for substituting a "knowledge-based economy" for one based on resources:

...that we can save the "growth forever" paradigm by dematerializing the economy, or "decoupling" it from resources, or substituting information for resources, is fantasy. (Daly 1996)

Not everyone agrees with Daly's concept of the economy as a subset of the ecosystem. It is more common to draw a diagram showing natural systems, social systems, and economic systems as mostly distinct, but with some limited area of overlap. Some ecologists even take a view opposite to Daly's, arguing that humans already dominate ecosystems to such an extent that the natural system is merely a subset of the social system:

There is no part of the natural system that is isolated from the social system because it is difficult to identify a natural system that has not been affected in the past or currently by humans... The yolk of the egg is the natural system, which is entirely embedded within the white of the egg, which is the social system. (Vogt et al. 1997)

Despite this divergence of opinion about how to depict the relationship between social, economic and natural systems, there is agreement on the importance of understanding how they interact. Forestry has always had to grapple with complex social and economic issues. But views of what constitute socio-economic research in forestry are changing:

Humans are the most understudied species in the forest despite the fact that it is the species with the greatest capacity to alter forest ecosystems. The notion that humans function outside nature is fading in the minds of the public and forest practioners alike. (Beckley 1995)

Human activities and infrastructures are parts of ecosystems, yet they often pose serious threats to ecosystem integrity.
Ecological approaches to resource management must be comprehensive and promote global-scale action, yet they must be differentiated to accommodate the great diversity of natural systems and human cultures. And although adaptive management approaches must deal with enormous complexity, they have to be simple enough to be understood by ordinary citizens.

These are some of the paradoxes that emerge when ecosystem concepts are applied in a policy context. The need to recognize socio-economic research as an integral part of forestry has never been greater.

\section{References}

Beckley, T. 1995. Sustainable forest development in Canada: Sociological perspectives. For. Chron. 71: 362-363.

Botkin, D.B. 1997. Getting the paradigm right: The essential ecological foundation for the conservation and sustainable management of British Columbia's forests and natural resources. The Leslie L. Schaffer Lectureship in Forest science. November 3, 1997. University of British Columbia, Vancouver, BC.

Canadian Council of Forest Ministers. 1998. National Forest Strategy (1998-2003). Sustainable forests: A Canadian commitment. CCFM Secretariat, Canadian Forest Service. Ottawa, ON.

Constanza, R., R. d'Arge, R. de Groot, S. Farber, M. Grasso, B. Hannon, K. Limburg, S. Naeem, R.V. O'Neill, J. Paruelo, R.G. Raskin, P. Sutton and M. van den Belt. 1997. The value of the worlds ecosystem services and natural capital. Nature 378: 253-260.

Daly, H.E. 1996. Beyond Growth. Beacon Press, Boston, MA.

Hendrickson, O. 1995. Adaptive ecosystem management. Forestry Chronicle 71: 358-359.

Holling, C.S. 1992. Cross-scale morphology, geometry, and dynamics of ecosystems. Ecological Monographs 62: 447-502.

May, R. 1998. Science and the climate change agenda post Kyoto. Lecture at the National Research Council. April 28, 1998. National Research Council of Canada. Ottawa, ON.

Michener, W.K., J.W. Brunt, J.T. Helly, T.B. Kirchner, and S.G. Stafford. 1997. Nongeospatial metadata for the ecological sciences. Ecological Applications 7: 330-342.

Myers, N. 1997. The world's forests and their ecosystem services. In G.C. Daily (ed.). Nature's services: Societal dependence on natural ecosystems. pp. 215-235. Island Press, Washington, DC.

OECD Megascience Forum. 1998. Draft report of the OECD Megascience Forum Working Group on Biological Informatics.

President's Committee of Advisers on Science and Technology. 1998. Teaming with life: Investing in science to understand and use America's living capital. Panel on Biodiversity and Ecosystems. Washington, DC. http://wwwl.whitehouse.gov/WH/EOP/OSTP/ Environment/html/teamingcover.html

Vogt, K.A., J.C. Gordon, J.P. Wargo, D.J. Vogt, H. Asbjornsen, P.A. Palmiotto, H.J. Clark, J.L. O'Hara, W.S. Keaton, T. PatelWeynand, and E. Witten. 1997. Ecosystems: Balancing science with management. Springer-Verlag, New York, NY. 